DOI: $10.2478 / \mathrm{adms}-2020-0023$

\author{
A. Sajek* \\ West Pomeranian University of Technology, Szczecin, Poland \\ *adam.sajek@zut.edu.pl
}

\title{
WELDING THERMAL CYCLES OF JOINTS MADE OF S1100QL STEEL BY SAW AND HYBRID PLASMA-MAG PROCESSES
}

\begin{abstract}
The aim of this article is to validate the method of conducting a multipoint temperature measurement in the area of welded joints as a tool for quality assessment of the joints in question. In order to establish a relationship between temperature readout at a given point, the value of heat input and the distance of the point form the weld axis, preliminary tests have been conducted on a set of padding welds. Correlation of measurement data analysis showed the high 0.99 level. In the second stage of the study, temperatures of joints welded with two different methods have been measured: the HPAW (Hybrid Plasma - Arc Welding) and classic SAW (Submerged Arc Welding) method. The obtained temperature curves reflect the intensity of heat input in a given welding process. When compared to thermal effects on metallographic specimens, the shapes of the curves show a potential for quality assessment of joints in production conditions. Estimating thermal effects with classic analytical methods proves imprecise with respect to advanced high-power welding processes. Monitoring temperature will allow to assess the quality of joints in the course of welding, which may be a remarkable factor in terms of limiting the HAZ (heat affected zone) tempering of joints made from MART steels (advanced high strength martensitic steel) - a phenomenon that exceedingly decreases the strength of the joints. The method for quality assessment of welded joints presented in this paper allows to extend the analysis of welding thermal conditions.
\end{abstract}

Keywords: MART; structural steel; hybrid welding; HPAW; SAW; heat input; welding thermal cycle

\section{INTRODUCTION}

Martensitic advanced high-strength steels make it possible to manufacture self-supporting constructions which were impossible to obtain a few decades ago [1-3]. With their yield strength exceeding $1000 \mathrm{MPa}$, parts of self-propelled cranes and other automotive components made from such steels are much lighter, but retain their load capacity. This improves performance, lowers costs and increases the safety of operating conditions.

MART-type steels are fine-grain low-alloy quench-hardened construction steels. Their superior mechanical properties originated from the almost fully martensitic structure. They are characterised by high value of ultimate tensile strength, currently reaching ca. $2000 \mathrm{MPa}$, and low cold-shortness temperature. However, to retain the strength of such steels after a welding process is incredibly difficult, even though in the manufacturing process, they undergo high-temperature tempering in order to improve the thermal resistance of the structure $[4,5]$. 
Welding is a natural choice for joining constructions whenever the priority is to maximally reduce the influence joints have on the mass of such constructions. While there are numerous advantages of welding, the heat that accompanies the process adversely affects strength and induces steel tempering [6-9]. The intensity of tempering depends on the value of heat input which should be kept within narrow tolerance range. High heat input results in distortions which, in turn, require laborious straightening. Analogically, excessively low heat input can induce lack of joint penetration, hardness fluctuations resulting in brittleness, which lead to the deterioration of impact strength and the occurrence of cracks [10-13].

The paper focuses on welding large-size elements of self-propelled telescopic cranes (Fig. 1). Currently, the two longitudinal welds that join the halves of the boom tube are made with the SAW (Submerged Arc Welding) process. The process is characterised by a high efficiency of the welding arc that operates submerged beneath flux powder and thus allows to obtain high welding speeds and deep weld penetration [14]. Unfortunately, the process leads to high values of heat input that destabilise the martensitic structure of the base material $[3,15]$.

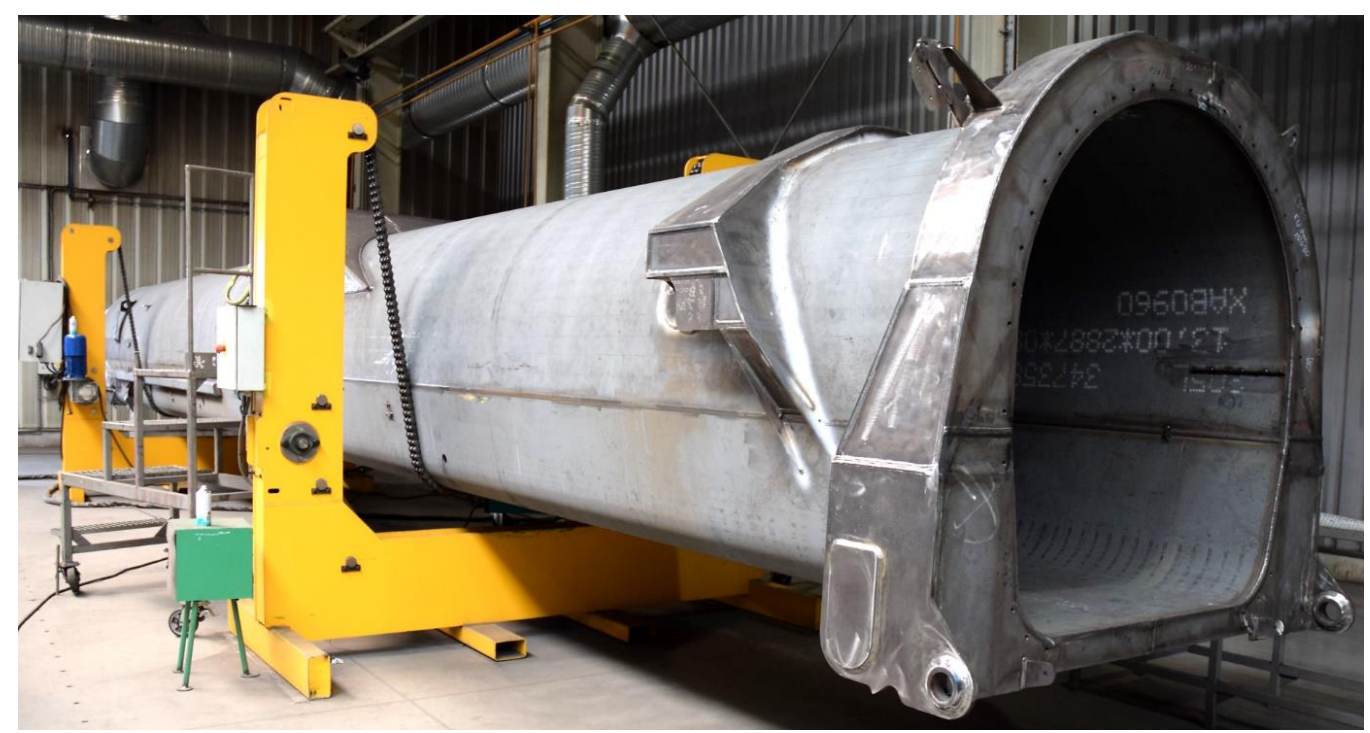

Fig. 1. The example of the part of lifting crane with a longitudinal weld connecting 2 halves of a telescopic tube

Advanced high-power processes are really promising in terms of low thermal interference into the structure of welded joints. One representative of this group of welding methods is HPAW which uses both a plasma and a MAG (Metal Active Gas) torch within a single welding head. The two arcs are concentrated within a single welding pool by means of external magnetic field created by pole pieces placed between the electrodes. The aim of the plasma process is to supply a concentrated heat beam into a joint in order to partially melt the edges of the groove. Then, the last step to make a correct joint is to fill the groove with filler metal, which is done by the MAG torch. Such task distribution makes it possible to reduce the groove angle and thus the amount of solidifying filler metal, which in turn, limits the extent of deformations. Since welding speeds in this process are higher than in SAW, the value of heat input gets reduced too [16-18]. In production conditions, a proper assessment of heat input becomes necessary in order to ensure optimum properties of joints in welded MART steels $[19,20]$.

So far, heat input has been estimated on the basis of the formula comprising the power of welding arc and the speed at which it moves along the welded edge. The classic heat input dependency, however, offers little precision for today's high-energy welding processes [21], 
[22]. In hybrid processes, for example, welding speed may exceed $70 \mathrm{~cm} / \mathrm{min}$. When high welding speeds are concerned, the degree to which a material can transfer and conduct heat starts playing an important role [22-26].

The assessment of heat input in production welding can be approached from a different perspective, i.e. one can study the thermal effects of welding by recording the temperature of a joint. In such case, however, measurement capability may pose a challenge [23,27-29]. Irrespective of the employed method of recording the temperature in a weld, there arise problems that exclude this spot from being utilised in production conditions. This paper makes an attempt to establish whether multipoint temperature measurement registered from a certain distance from a joint can possibly reflect the extent and character of heat input.

\section{MATERIALS AND METHODS}

The study made use of ThysenKrupp's S1100QL steel whose trade name is the highstrength special structural steel XABO ${ }^{\circledR} 1100$. Its chemical composition and properties are shown in Table 1.

Table 1. Chemical composition of $X A B O 1100$ steel. Mechanical properties: $R p_{0.2}=1258 \mathrm{MPa} ; R m=1397 \mathrm{MPa}$; $A=8 \% ; K V-40^{\circ} \mathrm{C}=32 \mathrm{~J}$. Manufacturer certificate data

\begin{tabular}{lccccccccccccc}
\hline Element & $\mathrm{C}$ & $\mathrm{Si}$ & $\mathrm{Mn}$ & $\mathrm{Cr}$ & $\mathrm{Mo}$ & $\mathrm{V}$ & $\mathrm{Ni}$ & $\mathrm{Cu}$ & $\mathrm{Al}$ & $\mathrm{B}$ & $\mathrm{P}$ & $\mathrm{S}$ & $\mathrm{Nb}+\mathrm{Ti}+\mathrm{Zr}$ \\
\hline Content, \% & .16 & .07 & 1.20 & .64 & .60 & .003 & 1.90 & .03 & .03 & .0002 & .009 & .001 & .03 \\
\hline
\end{tabular}

The study have been conducted in Telemond Holding Sp. z o.o. at Kostrzyn upon Odra private limited company with the aim of carrying out measurements for the HPAW (Plasma + MAG) process in production conditions (Fig.2).

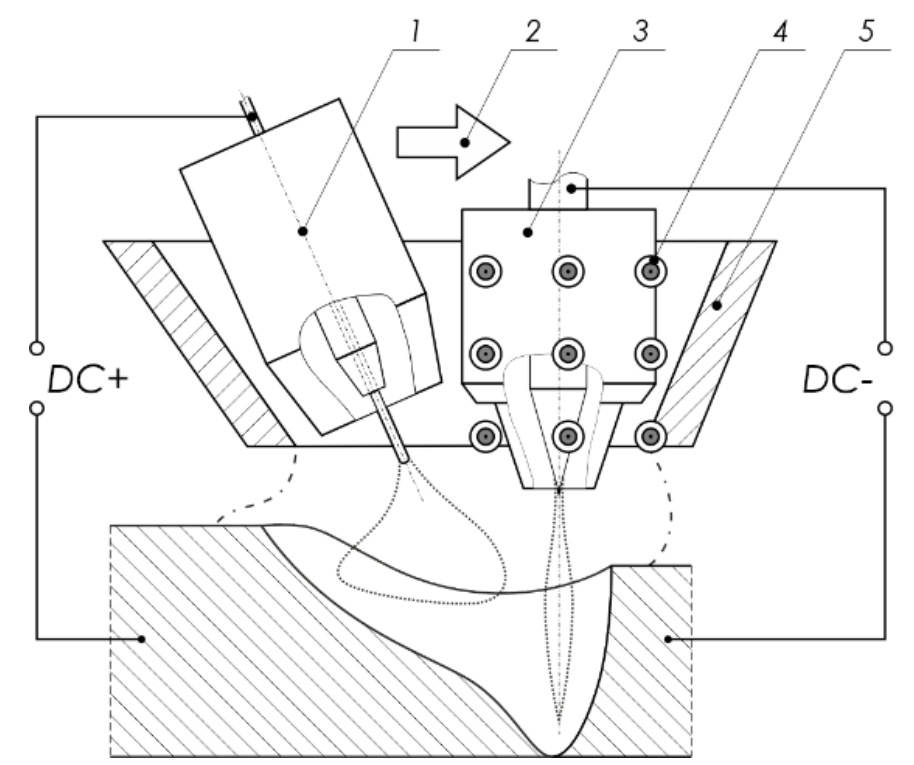

Fig. 2. Schematic diagram of HPAW process: 1 - MAG torch; 2 - welding direction; 3 - plasma torch; 4 magnetic field generator (arc focusing); 5 - shielding gas nozzle [27]

Experimental works consisted of 2 stages: 1. examination of the influence of heat input on the temperatures registered during a multipoint measurement in the area of a padding weld and 2. assessment of the measurement method as far as the character of heat input in a joint is 
concerned. In the second stage, the thermal effects of hybrid welding were compared with the SAW method that had been used so far.

The test stand for the hybrid process has been equipped with the arm of the Fanuc M20iA/35M robot featuring the Weldobot HD head for hybrid welding and operated from the Fronius TPSi 5000 and SuperMIG WCM-100 sources. The SAW process was conducted with the ESAB A2 Multitrac tractor operated from the ESAB LAF 635 power source.

Padding welds have been made on specimens that were $8 \mathrm{~mm}$ thick and welded joints have been made on sheets that were $8 \mathrm{~mm}$ thick (Fig. 3). V-bevelling has been used with the groove angle being $30^{\circ}$ and a pre-made back weld produced with the MAG method at a robotic welding station featuring an IGM robot. For the tests EN ISO 16834-A: G 795 M21 Mn4Ni1.5CrMo filler metal with a $1.2 \mathrm{~mm}$ diameter was used. The shielding gas Ar $4.5+21 \%$ $\mathrm{CO}_{2}$ (M21) with $12 \mathrm{l} / \mathrm{min}$ flow rate and the plasma gas $\mathrm{Ar} 4.5$ with $41 / \mathrm{min}$ flow rate were applied. For SAW process solid wire (2.4 mm diameter) and EN ISO 26304-A: S 696 FB SZ3Ni2.5CrMo H5 flux were used.

Temperature readout at the frequency of $1 \mathrm{~Hz}$ has been done with 4 type $\mathrm{K}$ thermocouples welded onto the surface of a sheet and connected to the RSG Weldotherm industrial recorder.

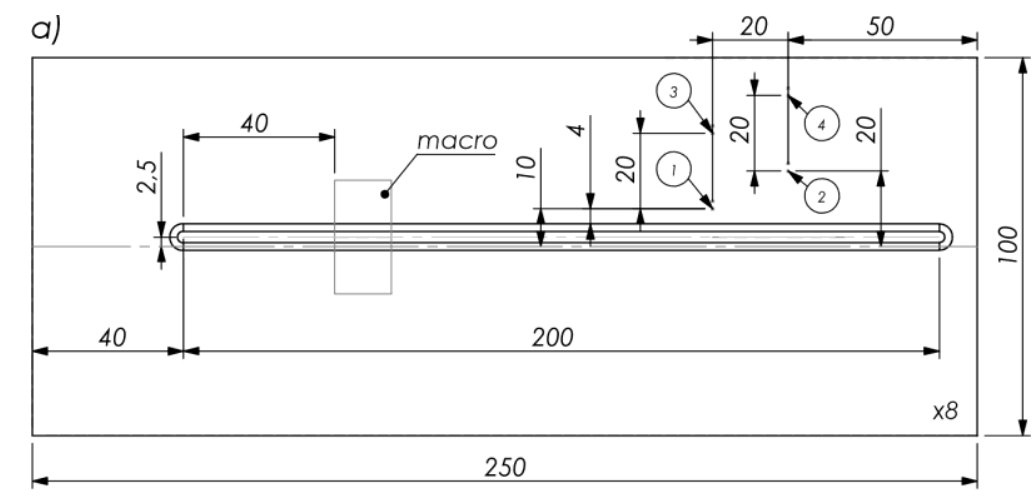

b)

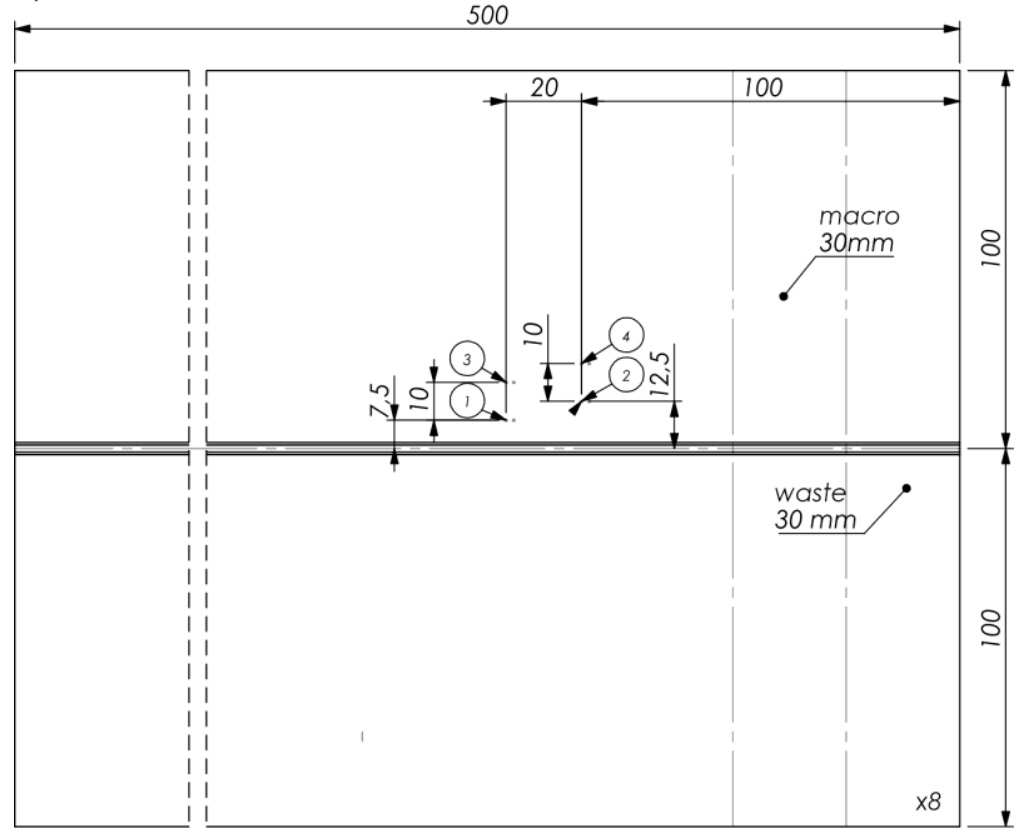

Fig. 3. Schematic diagrams of specimens used in the course of the study: a) padding welds made in the 1st stage; b) schematic diagram of a welded joint made in the 2nd stage. The spots where the thermocouples have been welded on are marked with digits 1, 2, 3, 4 
Table 2. Parameters for padding welds. Symbols: $v$ - welding speed; Ip, Up - plasma welding current and arc voltage; Im, Um - MAG welding current and arc voltage, $Q$ - heat input

\begin{tabular}{|c|c|c|c|c|c|c|}
\hline \multirow{2}{*}{ No } & \multirow{2}{*}{$\mathrm{v}, \mathrm{cm} / \mathrm{min}$} & \multicolumn{2}{|c|}{ Plasma } & \multicolumn{2}{|c|}{ MAG } & \multirow{2}{*}{$\mathrm{Q}, \mathrm{kJ} / \mathrm{cm}$} \\
\hline & & Ip, A & Up, V & $\mathrm{Im}, \mathrm{A}$ & $\mathrm{Um}, \mathrm{V}$ & \\
\hline 1 & 70 & 80 & 22.1 & 185 & 18.5 & 3.2 \\
\hline 2 & 80 & 115 & 23.4 & 270 & 23.3 & 5.0 \\
\hline 3 & 60 & 90 & 22.4 & 210 & 19.9 & 4.5 \\
\hline 4 & 110 & 85 & 21.7 & 296 & 23.2 & 3.6 \\
\hline 5 & 100 & 120 & 23.8 & 240 & 22.3 & 3.6 \\
\hline 6 & 90 & 105 & 23.8 & 208 & 19.8 & 3.2 \\
\hline 7 & 140 & 95 & 22.8 & 305 & 23.9 & 3.1 \\
\hline 8 & 120 & 110 & 24.1 & 231 & 22.7 & 2.9 \\
\hline 9 & 130 & 130 & 24.7 & 320 & 25.2 & 3.9 \\
\hline
\end{tabular}

\section{RESULTS}

In the first place, 9 padding welds have been made in accordance with the schematic diagram shown in Figure 3a. The parameters of the process are shown in Table 2. After the analysis of temperature-time diagrams (Fig. 4), the maximum temperature has been determined for each point.

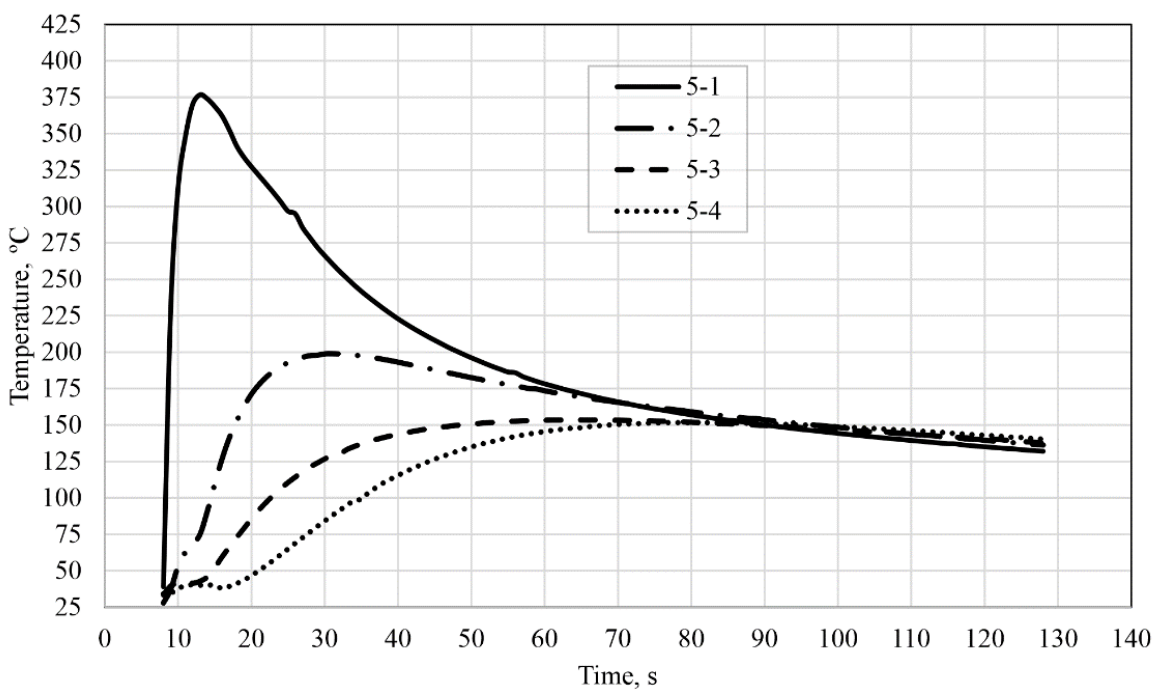

Fig. 4. The course of temperatures registered in points $1-4$ for the padding weld no. 5 , made at the speed of $100 \mathrm{~cm} / \mathrm{min}$ and with the heat input of $3.6 \mathrm{~kJ} / \mathrm{cm}$

In order to examine the dependence between heat input $\mathrm{Q}$ and the maximum temperature $\mathrm{T}_{\max }$ at a point located at a $\mathrm{y}$ - distance of thermocouple from the padding weld axis (1: 7.5 $\mathrm{mm} ; 2: 17.5 \mathrm{~mm} ; 3: 27.5 \mathrm{~mm} ; 4: 37.5 \mathrm{~mm}$ ), a correlation analysis has been done for the following dependence:

where: $\mathrm{a}$ - slope, $\mathrm{b}$ - intercept.

$$
T_{\max }=a \cdot \frac{Q}{y}+b T_{\max }=a \cdot \frac{Q}{y}+b
$$

For the correlation in question, the Pearson correlation coefficient reached the value of 
0.99, which shows a strong dependence between the maximum temperatures obtained through multipoint measurement and the parameters employed in the process of making a padding weld. The results of the analysis are shown in figure 5. The dependence between the analysed parameters, determined with linear regression method, takes the following form:

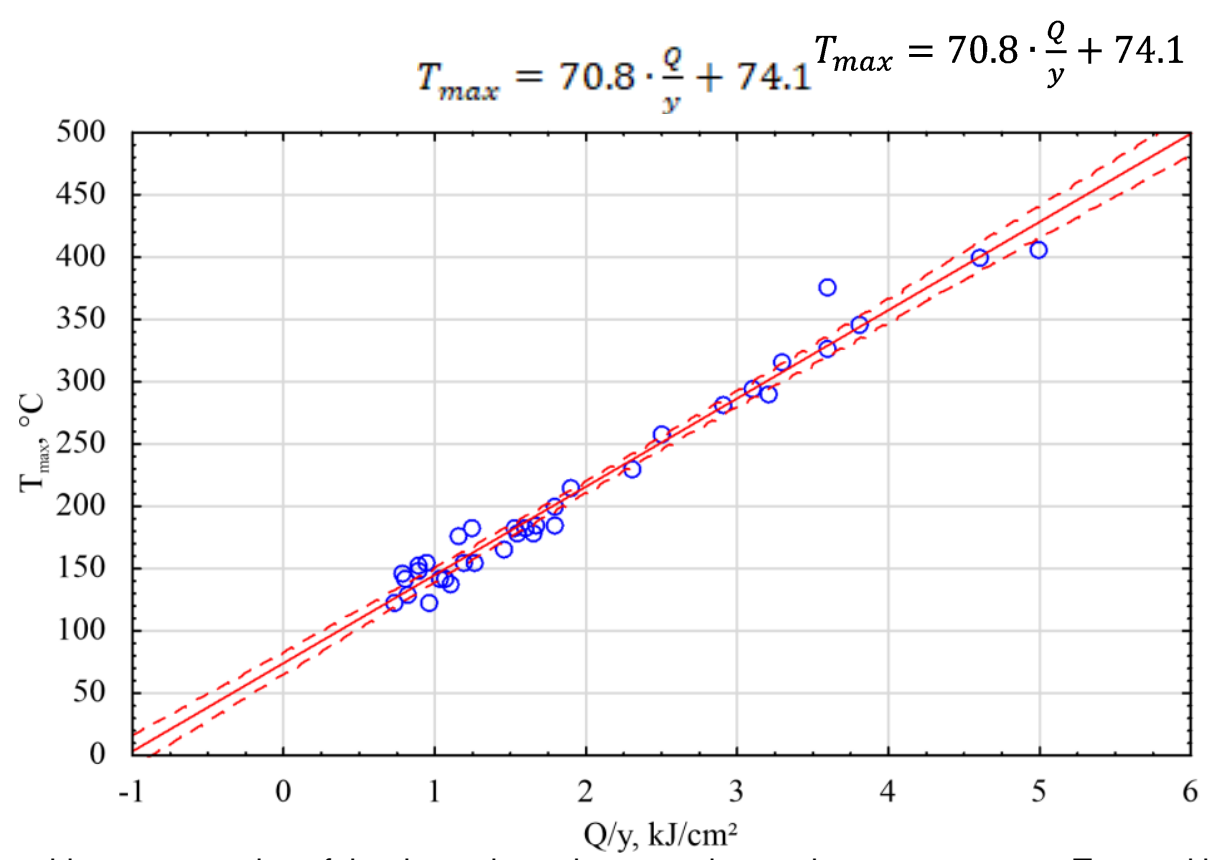

Fig. 5. Graphic representation of the dependence between the maximum temperature $T_{\max }$ and heat input with reference to the distance of the thermocouple from the padding weld axis $Q / y$

Once it had been established that multipoint temperature measurement proves highly useful for determining heat input, a decision has been made to establish whether it is possible to analyse the character of heat input with regard to welded joints. Thereby, 3 test joints have been made: one with the use of the hybrid method and two with the use of submerged arc welding. Welding joints parameters are based on previously performing arc stabilization tests.

The joint produced with the HPAW method has been welded at the speed of $70 \mathrm{~cm} / \mathrm{min}$ (low process value) with the following plasma parameters: Ip $=70 \mathrm{~A} ; \mathrm{Up}=30.9 \mathrm{~V}$ and for MAG: $\mathrm{Im}=146 \mathrm{~A} ; \mathrm{Um}=16.9 \mathrm{~V}$ (sample: HPAW70). As a consequence, heat input was equal to $2.8 \mathrm{~kJ} / \mathrm{cm}$.

An attempt at SAW at the speed of $70 \mathrm{~cm} / \mathrm{min}$ (max. available speed) - equivalent to the speed of the hybrid process - has also been made, and the following parameters have been set: $\mathrm{I}=234 \mathrm{~A} ; \mathrm{U}=22.1 \mathrm{~V}$ (sample: SAW70). In consequence, the value of heat input was higher and equal to $4.4 \mathrm{~kJ} / \mathrm{cm}$. However, at such speed, the process proved highly unstable. Third joint was made with a stable glow of the arc at a lower speed, i.e. $40 \mathrm{~cm} / \mathrm{min}$ (sample: SAW40), but with the same values of electric parameters. In this case, the calculated heat input was $7.9 \mathrm{~kJ} / \mathrm{cm}$.

Figure 6 shows the temperatures registered for the joints welded at the speed of 70 $\mathrm{cm} / \mathrm{min}$. Despite a higher value of heat input in the case of the SAW process, the observed thermal effect is less intense. The temperatures registered for the HPAW process, where the calculated heat input was lower, have higher values.

A comparison of the temperature measurements of the above mentioned three joints shows that the various welding methods have their own distinctive character. The greatest disparities can be observed with reference to point 1, closest to the weld axis (Fig. 7a). What can be observed for HPAW is a sharp rise in temperature, with the maximum being $30 \%$ higher than in the case of the joints produced with the SAW method, and high cooling rate. 
The shape of the curve for the joint produced with the SAW method at high speed indicates a similarly rapid temperature increase. One can also see a characteristic peak. As regards SAW at the speed of $40 \mathrm{~cm} / \mathrm{min}$, the registered temperature is lower even from the temperature of the equivalent joint produced at a higher speed despite the heat input being higher. The shape of the curve for this joint suggests a rather steady character of the process. The obvious explanation for this phenomenon may be a different heat balance resulting from the limitation of heat flow to the environment due to the use of welding flux in the SAW process [30].
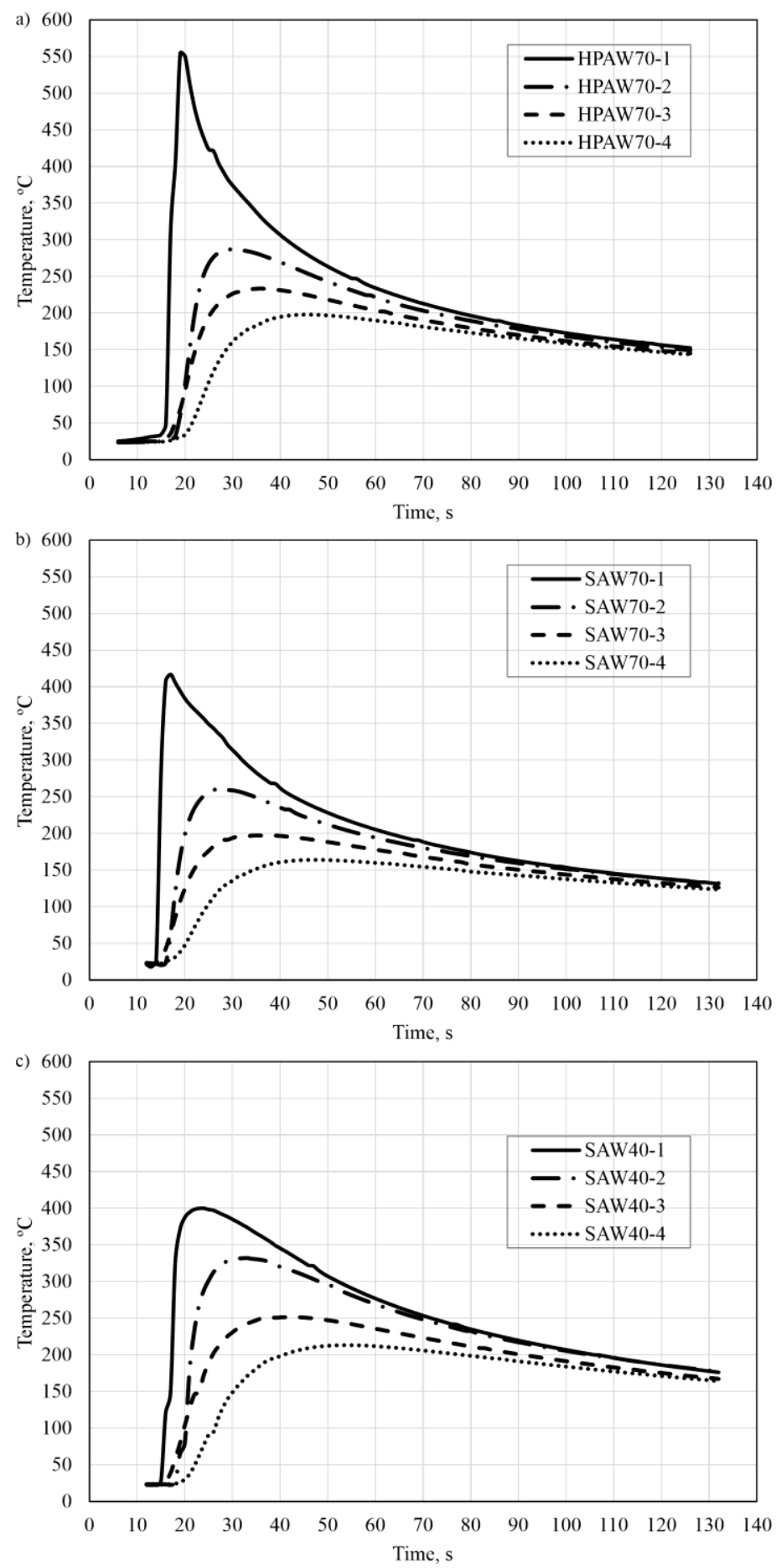

Fig. 6. Temperatures of welding processes performed at the speed of 40 and $70 \mathrm{~cm} / \mathrm{min}$ registered via multipoint measurement: a) hybrid $Q=2.8 \mathrm{~kJ} / \mathrm{cm}$; b) $S A W Q=4.4 \mathrm{~kJ} / \mathrm{cm}$; c) $S A W Q=7.9 \mathrm{~kJ} / \mathrm{cm}$ 

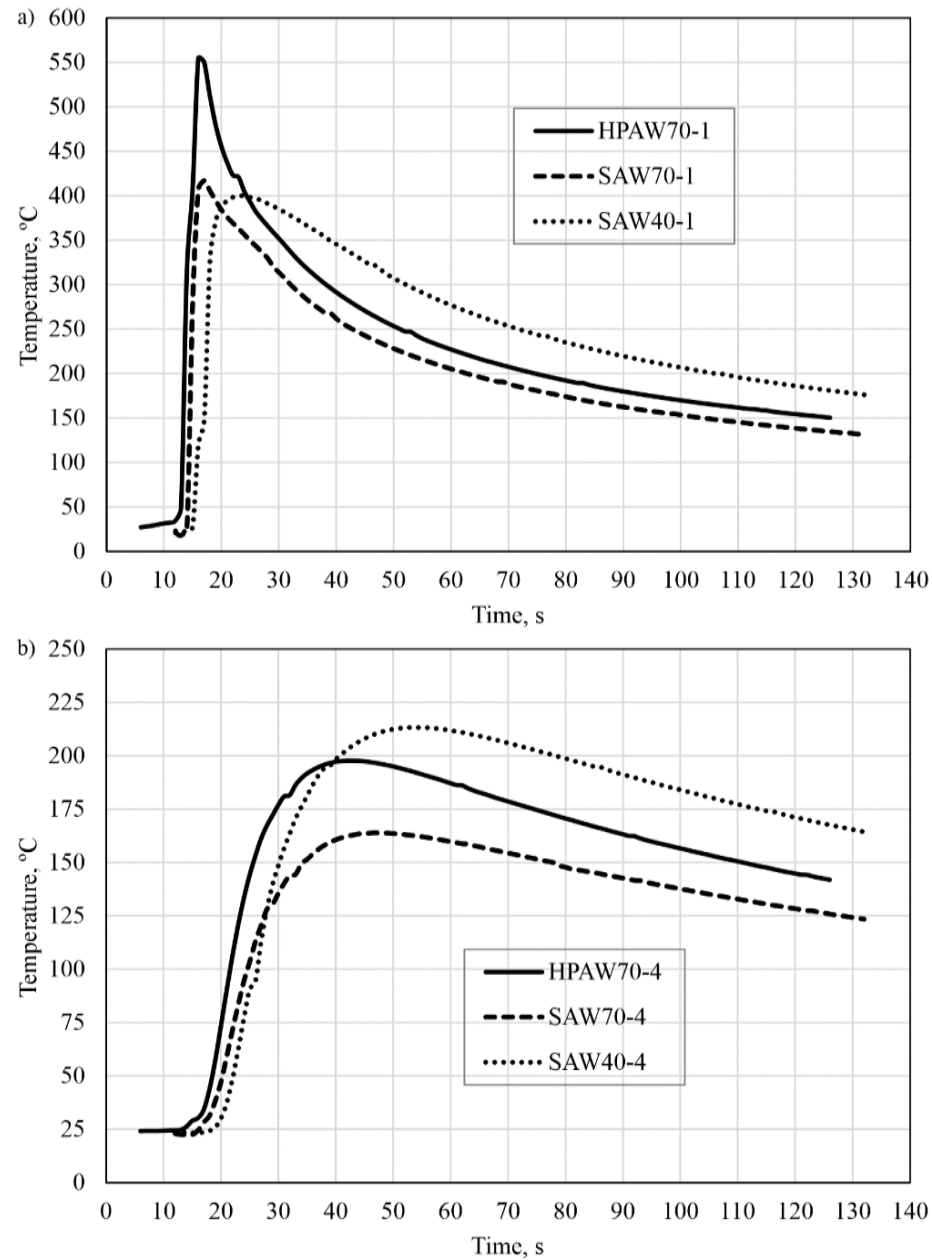

Fig. 7. Comparison of thermal effects registered in the following locations: a) point 1, closest to the joint; b) point 4 , furthest from the joint

At the same time, the temperature curves registered in the outermost point 4 are completely different (Fig. 7b). In this area, the temperature rise has a similar shape for every joint. Dissimilarities are especially prone with regard to maximum temperature values which are the highest for the joint with the highest heat input. The second highest maximum temperature value can be observed for the hybrid process. By contrast, the lowest values are the ones for the SAW joint produced at the speed of $70 \mathrm{~cm} / \mathrm{min}$.

In order to visualise thermal effects of the processes in question, macroscopic examinations have been conducted. Resultant images can be seen in figure 8 .

As far as hybrid welding is concerned, a deep and narrow fusion can be observed; such fusions are characteristic for advanced high power welding processes. Unfortunately, the SAW process, for which similar bevelling and comparable parameters had been employed, have not allowed to obtain full joint penetration. The metallographic specimens illustrating the quality of the joints are consistent with the temperature results shown in the diagram in figure ta. Heat input is commensurate with the penetrated weld area and heat affected zone; however, it does not fully reflect the good quality of the joint.

The relationship between heat input $\mathrm{Q}$, maximum temperature registered in the point of measurement $\mathrm{T}_{\max }$ and the distance of the point from the joint axis $\mathrm{y}$ is shown in the $\mathrm{T}_{\max }=$ $\mathrm{f}(\mathrm{Q} / \mathrm{y})$ diagram (Fig. 9). The cooling dynamics of a given process is illustrated by the slope which reaches the highest value for high-power hybrid welding (HPAW70). Lower value of 
the coefficient that can be observed for the SAW70 specimen welded at the same speed, indicates lower arc efficiency. The lowest cooling dynamics can be observed for the SAW40 process. In the case of welding S1100QL steel, high efficiency of the arc allows to obtain fusion at high speeds, which minimises $t_{8 / 5}$ cooling time, ensuring minimum influence of welding heat on reducing strength in the heat-affected zone.
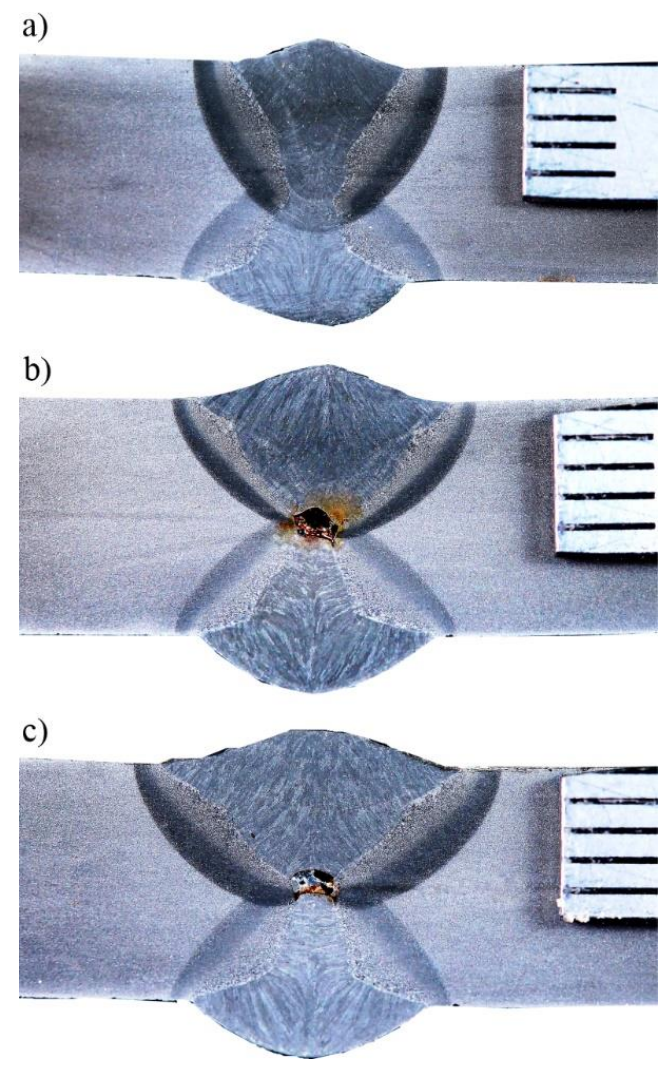

Fig. 8. Metallographic specimens for the examined joints: a) HPAW v $=70 \mathrm{~cm} / \mathrm{min} ; \mathrm{Q}=2.8 \mathrm{~kJ} / \mathrm{cm}$; b) $S A W v=70$ $\mathrm{cm} / \mathrm{min} ; 4.4 \mathrm{~kJ} / \mathrm{cm}$; c) SAW v $=40 \mathrm{~cm} / \mathrm{min} ; \mathrm{Q}=7.9 \mathrm{~kJ} / \mathrm{cm}$. No joint penetration can be observed due to welding parameters being too low

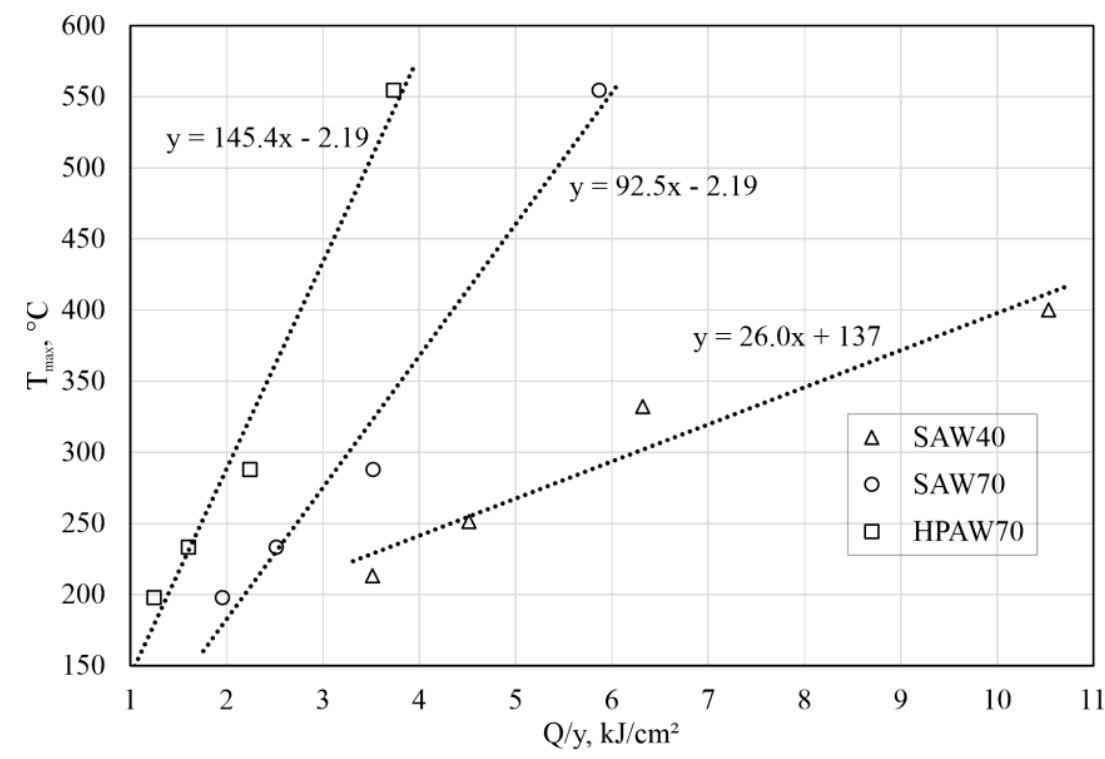

Fig. 9. Graphic representation of the dependence between the maximum temperature $T_{\max }$ and heat input with reference to the distance of the thermocouple from the welded joint axis $Q / y$ 


\section{SUMMARY}

The article introduced a method for quality assessment of welded joints that involves multipoint temperature measurements in the area of the weld. The method proved useful in the context of welding advanced high strength steels. An investigation of the differences in the values of heat input for different types of welded joints allowed to formulate the following conclusions:

- the HPAW process, despite lower calculated heat input, allows to reach higher temperature values. In consequence, the edges of a weld groove are heated and remelted in a more effective way. The sharp temperature drop that accompanies the process limits overheating of a joint and thus lowers the tendency for tempering and strength loss in the HAZ;

- a further increase in welding speed, along with simultaneous intensification of process parameters, may enhance the abovementioned effects, and thus increase the strength of joints made from MART-type steels;

- the curves demonstrate the intensity of heating of the joints, irrespective of the calculated values of heat input, unravelling the actual course of welding. They can be used for quality assessment of joints at the stage of conducting welding procedures;

- the presented methodology shows high potential for quality assessment of welded joints in industrial practice, where employing complex measuring procedures and using expensive, sensitive equipment in difficult conditions is problematic. However, the methodology needs to be perfected by means of normalising the distance from the weld axis and collected collecting data, so as to determine calibration curves for joints that display the optimum values.

The author would like to thank Telemond Holding Sp. z o.o. private limited company for creating favourable conditions for conducting the study described in the article.

ORCID iD:

Adam Sajek: 0000-0003-0126-2654

\section{REFERENCES}

1. C. Lesch, N. Kwiaton, and F. B. Klose, "Advanced High Strength Steels (AHSS) for Automotive Applications - Tailored Properties by Smart Microstructural Adjustments" Steel Res. Int., vol. 88, no. 10, pp. 1-21, 2017.

2. S. Maggi and M. Murgia, "Introduction to the metallurgic characteristics of advanced highstrength steels for automobile applications" Weld. Int., vol. 22, no. 9, pp. 610-618, 2008.

3. H. Spindler, M. Klein, R. Rauch, A. Pichler, and P. Stiaszny, "High Strength and Ultra High Strength Hot Rolled Steel Grades - Products for Advanced Applications," BHM B. und Hüttenmännische Monatshefte, vol. 157, no. 3, pp. 108-112, 2012.

4. J. Klett, I. B. F. Mattos, H. J. Maier, R. H. G. e Silva, and T. Hassel, "Control of the diffusible hydrogen content in different steel phases through the targeted use of different welding consumables in underwater wet welding" Mater. Corros., no. 9, pp. 1-13, 2020.

5. M. S. Węglowski, M. Zeman, and A. Grocholewski, "Effect of welding thermal cycles on 
microstructure and mechanical properties of simulated heat affected zone for a Weldox 1300 ultra-high strength alloy steel” Arch. Metall. Mater., vol. 61, no. 1, pp. 127-132, 2016.

6. W. Guo, D. Crowther, J. A. Francis, A. Thompson, Z. Liu, and L. Li, "Microstructure and mechanical properties of laser welded S960 high strength steel” Mater. Des., vol. 85, pp. 534$548,2015$.

7. A. Świerczyńska and M. Landowski, "Plasticity of bead-on-plate welds made with the use of stored flux-cored wires for offshore applications" Materials, vol. 13, no. 17, 3888, 2020.

8. D. Fydrych, J. Łabanowski, J. Tomków, and G. Rogalski, "Cold Cracking Of Underwater Wet Welded S355G10+N High Strength Steel” Adv. Mater. Sci., vol. 15, no. 3, pp. 48-56, 2015.

9. F. Hochhauser, W. Ernst, R. Rauch, R. Vallant, and N. Enzinger, "Influence of the soft zone on the strength of welded modern HSLA steels" Weld. World, vol. 56, no. 5-6, pp. 77-85, 2012.

10. A. M. Moreno-Uribe, A. Q. Bracarense, and E. C. P. Pessoa, "The effect of polarity and hydrostatic pressure on operational characteristics of rutile electrode in underwater welding" Materials, vol. 13, no. 21, 5001, 2020.

11. M. Szala, G. Winiarski, Ł. Wójcik, and T. Bulzak, "Effect of Annealing Time and Temperature Parameters on the Microstructure, Hardness, and Strain-Hardening Coefficients of 42CrMo4 Steel” Materials, vol. 13, no. 9, 2022, 2020.

12. L. Tuz, "Evaluation of microstructure and selected mechanical properties of laser beam welded S690QL high-strength steel" Adv. Mater. Sci., vol. 18, no. 3, pp. 34-42, 2018.

13. K. Pańcikiewicz, A. Zielińska-Lipiec, and E. Tasak, "Cracking of high-strength steel welded joints" Adv. Mater. Sci., vol. 13, no. 3, pp. 76-85, 2013.

14. J. Roy J., R. Chakraborti, R. N. Rai, S. C. Saha, "Studies on microstructure and mechanical properties of modified $9 \mathrm{Cr}-1 \mathrm{Mo}$ (P91) steel in submerged arc welding with $\mathrm{TiO}_{2}$-enriched fluxes” J. Braz. Soc. Mech. Sci. \& Eng., vol. 41, no. 10, 468, 2019.

15. M. Fiedler, R. Rauch, R. Schnitzer, W. Ernst, G. Simader, and J. Wagner, "The alform ${ }^{\circledR}$ welding system The world's first system for high-strength welded structures" IIW International Conference High-Strength Materials - Challenges and Applications, Helsinki, Finland, pp. 1-5, 2015.

16. B. Skowronska, T. Chmielewski, D. Golanski, and J. Szulc, "Weldability of S700MC steel welded with the hybrid plasma + MAG method" Manuf. Rev., vol. 7, no. 4, pp. 1-15, 2020.

17. T. Yang, L. Chen, Y. Zhuang, J. F. Liu, and W. L. Chen, "Arcs interaction mechanism in PlasmaMIG hybrid welding of 2219 aluminium alloy" J. Manuf. Process., vol. 56, no. 4, pp. 635-642, 2020.

18. Z. Xin, Z. Yang, H. Zhao, and Y. Chen, "Comparative study on welding characteristics of laserCMT and plasma-CMT hybrid welded AA6082-T6 aluminum alloy butt joints" Materials, vol. 12, no. 20, 3300, 2019.

19. A. Beniyash, G. Klimov, and T. Hassel, "The use of non-vacuum electron beam (NVEB) technology as an universal manufacturing process for welding and cutting of high-strength steels" J. Phys. Conf. Ser., vol. 1089, no. 1, pp. 1-9, 2018.

20. M. Amraei et al., "Mechanical properties and microstructural evaluation of the heat-affected zone in ultra-high strength steels" Thin-Walled Struct., vol. 157, no. 9, pp. 1-11, 2020.

21. K. Kudła and K. Wojsyk, "Czy sposób doprowadzania ciepła ma istotny wpływ na geometrię spoin?” Biul. Inst. Spaw., vol. 56, no. 5, pp. 140-144, 2012.

22. K. Kudła and K. Wojsyk, "Ocena ilości ciepła wprowadzonego w procesach spawania łukowego elektrodą topliwą w osłonie gazów ochronnych" Biul. Inst. Spaw., vol. 54, no. 5, pp. 121-126, 2010 . 
23. K. Yurtisik, S. Tirkes, I. Dykhno, C. H. Gur, and R. Gurbuz, "Characterization of duplex stainless steel weld metals obtained by hybrid plasma-gas metal arc welding" Soldag. Inspeção, vol. 18, no. 3, pp. 207-216, 2013.

24. T. Kik and J. Górka, "Numerical Simulations of Laser and Hybrid S700MC T-Joint Welding" Materials, vol. 12, no. 3, 516, 2019.

25. J. Nowacki and A. Sajek, "Verification of Properties of Joints Made of Advances High Strength Steels in the Conditions of the Complex Thermal Cycles of the HPAW Process" Biul. Inst. Spaw., vol. 62, no. 5, pp. 167-173, 2018.

26. K. Banerjee, "Improving weldability of an advanced high strength steel by design of base metal microstructure" J. Mater. Process. Technol., vol. 229, pp. 596-608, 2016.

27. A. Sajek and J. Nowacki, "Comparative evaluation of various experimental and numerical simulation methods for determination of $t 8 / 5$ cooling times in HPAW process weldments" Arch. Civ. Mech. Eng., vol. 18, no. 2, pp. 583-591, 2018.

28. Y. Yi, K. Wang, S. Zheng, J. Yi, and L. Xu, "Narrow gap gas metal arc welding of S890QL steel" IIW International Conference High-Strength Materials - Challenges and Applications, Helsinki, Finland, pp. 5-8, 2015.

29. J. Winczek, M. Gucwa, and K. Makles, "Analysis of thermal cycles and phase transformations during multi-pass arc weld surfacing of steel casts taking into account heat of the weld" J. Appl. Math. Comput. Mech., vol. 17, no. 1, pp. 89-100, 2018.

30. L. Sharma and R. Chhibber, "Investigations of Surface Properties of SAW Fluxes Using CaO$\mathrm{SiO} 2-\mathrm{TiO} 2$ \& Al2O3-CaO-SiO2 Ternary Phase Systems” Silicon 2020 (in Press). 